\title{
Locally Advanced Pancreatic Cancer: Percutaneous Management Using Ablation, Brachytherapy, Intra-arterial Chemotherapy, and Intra-tumoral Immunotherapy
}

\author{
Florentine E.F. Timmer $^{1}$ (D) Bart Geboers ${ }^{1} \cdot$ Sanne Nieuwenhuizen ${ }^{1} \cdot$ Evelien A.C. Schouten ${ }^{1} \cdot$ Madelon Dijkstra $^{1}$. \\ Jan J.J. de Vries ${ }^{1} \cdot$ M. Petrousjka van den Tol $^{2} \cdot$ Tanja D. de Gruijl ${ }^{3} \cdot$ Hester J. Scheffer $^{1} \cdot$ Martijn R. Meijerink $^{1}$
}

Accepted: 11 March 2021 / Published online: 17 April 2021

(C) The Author(s) 2021

\begin{abstract}
Purpose of Review Pancreatic ductal adenocarcinoma (PDAC) is one of the most aggressive neoplasms, bearing a terrible prognosis. Stage III tumors, also known as locally advanced pancreatic cancer (LAPC), are unresectable, and current palliative chemotherapy regimens have only modestly improved survival in these patients. At this stage of disease, interventional techniques may be of value and further prolong life. The aim of this review was to explore current literature on locoregional percutaneous management for LAPC.

Recent Findings Locoregional percutaneous interventional techniques such as ablation, brachytherapy, and intra-arterial chemotherapy possess cytoreductive abilities and have the potential to increase survival. In addition, recent research demonstrates the immunomodulatory capacities of these treatments. This immune response may be leveraged by combining the interventional techniques with intra-tumoral immunotherapy, possibly creating a durable anti-tumor effect. This multimodality treatment approach is currently being examined in several ongoing clinical trials.

Summary The use of certain interventional techniques appears to improve survival in LAPC patients and may work synergistically when combined with immunotherapy. However, definitive conclusions can only be made when large prospective (randomized controlled) trials confirm these results.
\end{abstract}

Keywords Locally advanced pancreatic cancer - Ablation - Radiofrequency ablation · Microwave ablation · Cryoablation . Irreversible electroporation $\cdot$ Brachytherapy $\cdot$ Intra-arterial chemotherapy $\cdot$ Intra-tumoral immunotherapy

This article is part of the Topical Collection on Interventional Oncology

Florentine E.F. Timmer

f.timmer1@amsterdamumc.nl

Bart Geboers

b.geboers@amsterdamumc.nl

Sanne Nieuwenhuizen

s.nieuwenhuizen1@amsterdamumc.nl

Evelien A.C. Schouten

e.schouten@amsterdamumc.nl

Madelon Dijkstra

m.dijkstra3@amsterdamumc.nl

Jan J.J. de Vries

j.devries1@amsterdamumc.nl

M. Petrousjka van den Tol

mp.vandentol@amsterdamumc.nl
Tanja D. de Gruijl

td.degruij1@amsterdamumc.nl

Hester J. Scheffer

hj.scheffer@amsterdamumc.nl

Martijn R. Meijerink

mr.meijerink@amsterdamumc.nl

1 Department of Radiology and Nuclear Medicine, Amsterdam UMC (location VUmc), De Boelelaan 1117, 1081, HV

Amsterdam, The Netherlands

2 Department of Surgical Oncology, Amsterdam UMC (location VUmc), De Boelelaan 1117, 1081, HV Amsterdam, The Netherlands

3 Department of Medical Oncology, Amsterdam UMC (location VUmc)-Cancer Center Amsterdam, De Boelelaan 1117, 1081, HV Amsterdam, The Netherlands 


\section{Introduction}

Pancreatic ductal adenocarcinoma (PDAC) remains a highly lethal disease, among some of the most challenging neoplasms to treat [1]. Despite advances in systemic regimens (i.e., stronger chemotherapeutics and novel immunotherapies), long-term survival can currently only be achieved through surgical resection of the tumor. However, even then, most patients will develop recurrent disease in the subsequent years, resulting in a 5year survival of $20 \%$ for resected patients [2]. At initial diagnosis, 30-40\% of patients present with locally advanced pancreatic cancer (LAPC, stage III) [3]. Herein, LAPC is defined as having $>180^{\circ}$ arterial engagement and/or venous involvement, rendering reconstruction unattainable [4]. Although palliative FOLFIRINOX (folinic acid, fluorouracil, irinotecan, and oxaliplatin) is currently the gold standard for stage III tumors, studies have suggested that locoregional treatments may improve overall and disease-free survival $[5 \cdot \bullet, 6,7 \cdot, 8-12]$. Percutaneous interventional techniques include radiofrequency ablation (RFA), microwave ablation (MWA), cryoablation, irreversible electroporation (IRE), brachytherapy (iodine$125\left({ }^{125} \mathrm{I}\right)$ seed implantation), intra-arterial infusion of chemotherapy (IAIC), and transarterial chemoembolization (TACE).

Another disconcerting feature of PDAC is its highly immunosuppressive tumor microenvironment (TME), established by, among others, the presence of regulatory T-cells (Tregs), myeloid-derived suppressor cells (MDSCs), and tumor-associated macrophages (TAMs) (Fig. 1), limiting the efficacy of chemo- and immunotherapies. In addition to their cytoreductive abilities, ablative, radiotherapeutic, and certain chemotherapeutic strategies have demonstrated immunomodulatory properties by inducing immunogenic cell death (ICD) [13, 14]. The destruction of tumor tissue releases antigens (i.e. proteins of mutated genes) and damage-associated molecular patterns (DAMPs), which are host biomolecules (e.g., DNA, RNA, cytokines) that promote and exacerbate an inflammatory response. These products promote activation of antigenpresenting cells (APCs) such as dendritic cells (DCs), which will subsequently transport antigens to the draining lymph nodes. Here, activation of anti-tumor-specific Tcells is established, theoretically capable of inducing a systemic anti-tumor response in which secondary, nonlocally treated tumors display regression [15]. The immune response may be leveraged by combining these tumor-destructive interventional techniques with immunotherapy. This review will focus on locoregional management of LAPC using ablative techniques, internal radiation (brachytherapy), intra-arterial chemotherapy, and intra-tumoral immunotherapy.

\section{Locoregional Ablation, Brachytherapy, Chemotherapy, and Immunotherapy}

Literature from the last decade (2010-2020) describing minimally invasive approaches (i.e., percutaneously or using an endoscope) of ablative techniques (RFA, MWA, cryotherapy, and IRE), brachytherapy (iodine-125 seed implantation), intra-arterial administration of chemotherapeutics (IAIC and TACE), and intra-tumoral immunotherapy is discussed. Specifically, safety and efficacy of these approaches (Tables 1 and 2) are addressed along with their immunomodulatory abilities.

\section{Radiofrequency Ablation}

RFA employs high-frequency alternating currents that create heat, achieving temperatures between 60 and $100^{\circ} \mathrm{C}$, resulting in acute lethal hyperthermia without an excessive increase in impedance [34]. In principle, the extent of cellular damage depends on three factors: amount of energy applied, rate of the energy delivery, and the tissue's sensitivity to thermal damage. Lethal hyperthermia $\left(>50-60{ }^{\circ} \mathrm{C}\right.$ ) induces tissue coagulation and protein denaturation in the central zone, in close proximity to the needle electrode. In the periphery, (sub)lethal temperatures $\left(<40-50^{\circ} \mathrm{C}\right)$ may result in a combination of necrosis, apoptosis, or recovery, depending on the exposure time [35]. Commonly, one needle electrode is used which is placed into the tumor core, either during laparotomy or laparoscopy, percutaneously, or endoscopically.

\section{Efficacy and Safety of RFA}

Within the management of pancreatic cancer, endoscopic ultrasound (EUS)-guided RFA has been successfully used for pain palliation by targeting the celiac ganglion [36]. However, the additive value of cytoreductive RFA in the context of LAPC remains controversial, regardless of the utilized method (i.e., open [37-43], percutaneous [16], endoscopic [44-46]). Literature on minimally invasive (percutaneous or endoscopic) RFA is scarce. Three articles employed EUS and one utilized a percutaneous approach. With a median overall survival (mOS) of 6 months from cytoreductive RFA, outcome was poor. Compared to the open approach, these methods demonstrated significantly reduced morbidity (0\% vs. $53 \%)$ and mortality ( $0 \%$ vs. $6 \%$ ). D'Onofrio et al. reported on the only percutaneous series of patients with unresectable PDAC $(n=$ 18 ), all of whom were pre-treated with chemotherapy [16]. Technical success was achieved in 16 patients $(93 \%)$, mOS was 6 months, and none of the patients experienced major complications. Most frequently reported severe complications for pancreatic RFA include pancreatitis, biliary injury, portal vein thromboses, pancreatic fistulas, hemorrhages, duodenal perforations, and gastric ulcers or fistulas [47]. The 


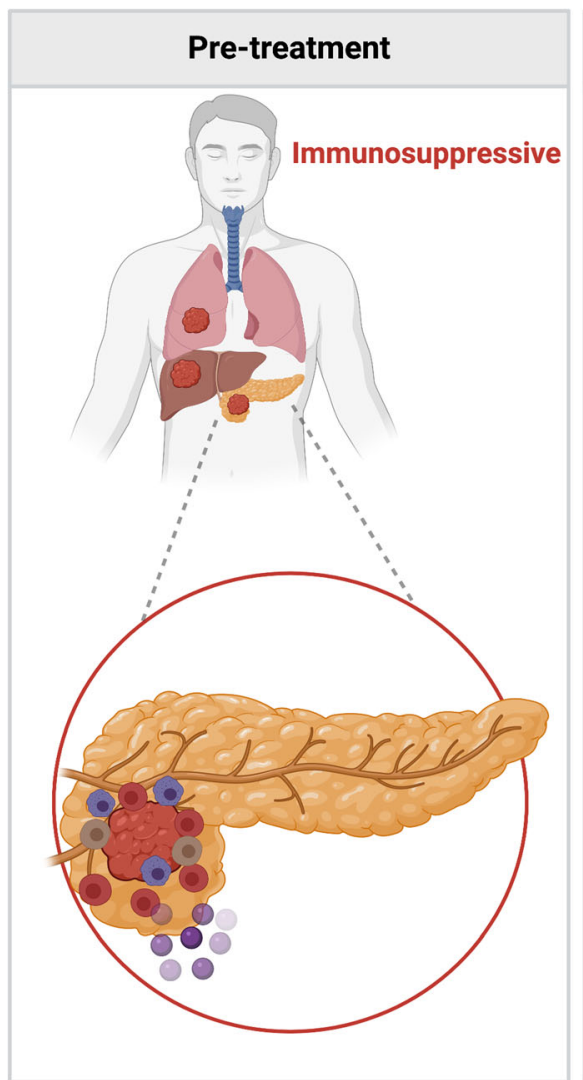

regulatory T-cell (Treg)

tumor-associated macrophage (TAM)

- myeloid derived suppressor cell (MDSC)

$\therefore \quad$ suppressive cytokines

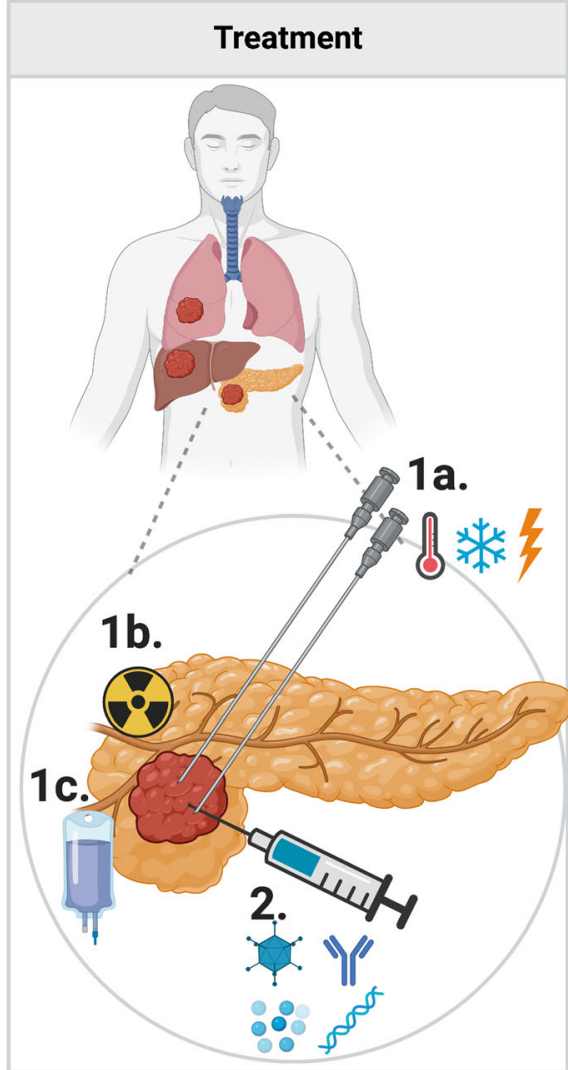

1a. needle-guided ablation (RFA, MWA, cryoablation, IRE)

1b. brachytherapy

1c. intra-arterial chemotherapy

2. intra-tumoral immunotherapy:

oncolytic virus

1) immune checkpoint inhibitor

permissive cytokines

$\overbrace{}^{\delta}$ toll-like receptor agonist

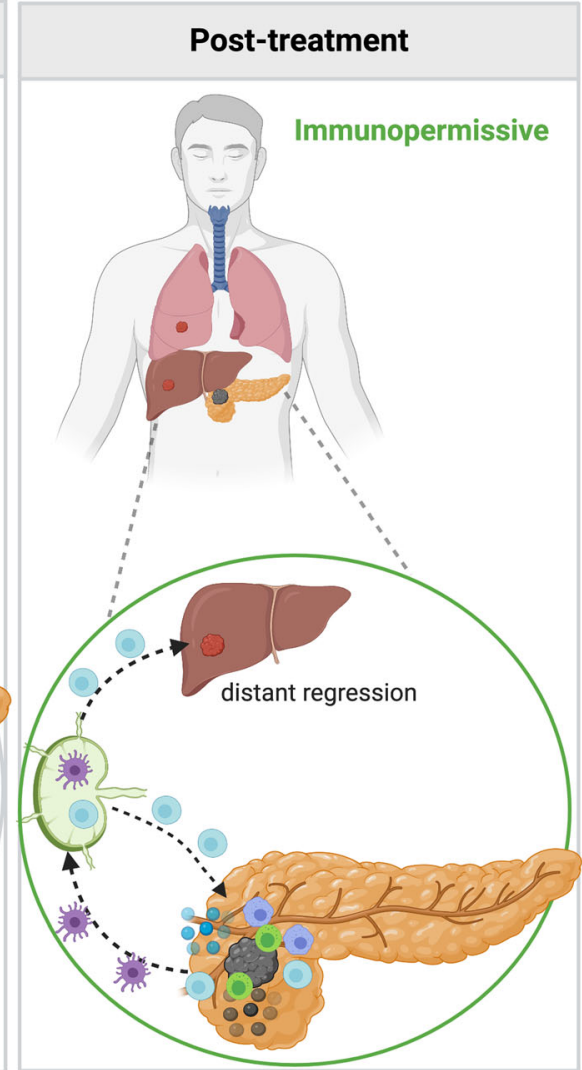

endritic cell (DC)

anti-tumor T-cells (Th1, CD8+)

M1 macrophage

$\because$ antigens + DAMPs

$\because$ permissive cytokines (type I IFN)

- natural killer cell
Fig. 1 Changing immune status upon treatment with local interventional treatment in combination with local immunotherapy. Pre-treatment: pancreatic ductal adenocarcinoma (PDAC) maintains a heavily immunosuppressive environment, established by (among others) regulatory T-cells (Tregs), tumor-associated macrophages (TAMs), myeloid-derived suppressor cells (MDSCs), and suppressive cytokines. Treatment: combination treatment with intra-tumoral immune modulation and ablation, brachytherapy, or intra-arterial chemotherapy potentially creates synergism resulting in a durable anti-tumor effect. Immune potentiation combined with local ablation leads to the release of tumor antigens and damage-associated molecular patterns (DAMPs). Subsequently activated dendritic cells (DCs) are now able to capture

positioning of the pancreas, entwined with delicate structures, complicates the utilization of thermal ablative methods. For example, the heat-sink effect of adjacent large blood vessels can hinder successful RF ablation. Also, to ensure minimal antigens and migrate towards the draining lymph nodes. Here, antigens are presented to lymphocytes, inducing antigen-specific expansion of effector T-cells, including T-helper-1 cells (Th1) and $\mathrm{CD}^{+}$(cytotoxic) T-cells, which will provide systemic anti-tumor immunity. Immune activation will lead to reduced TAMs, Tregs and MDSCs. Posttreatment: The tumor microenvironment demonstrates a more immunopermissive state, comprising of natural killer cells, M1 macrophages, anti-tumor T-cells (Th1 and $\mathrm{CD} 8^{+}$), and permissive cytokines such as interferon (IFN). T-cells are also primed to roam the body in search of tumor cells, both at the primary tumor site as well as other locations, possibly resulting in the regression of untreated concomitant (micro)metastases. Figure created with BioRender.com

collateral thermal damage, a safe distance to delicate surrounding parenchyma (i.e., blood vessels and duodenum) must be maintained [48]. This can be minimized by constant intra-procedural cooling of such structures. Ambiguity 


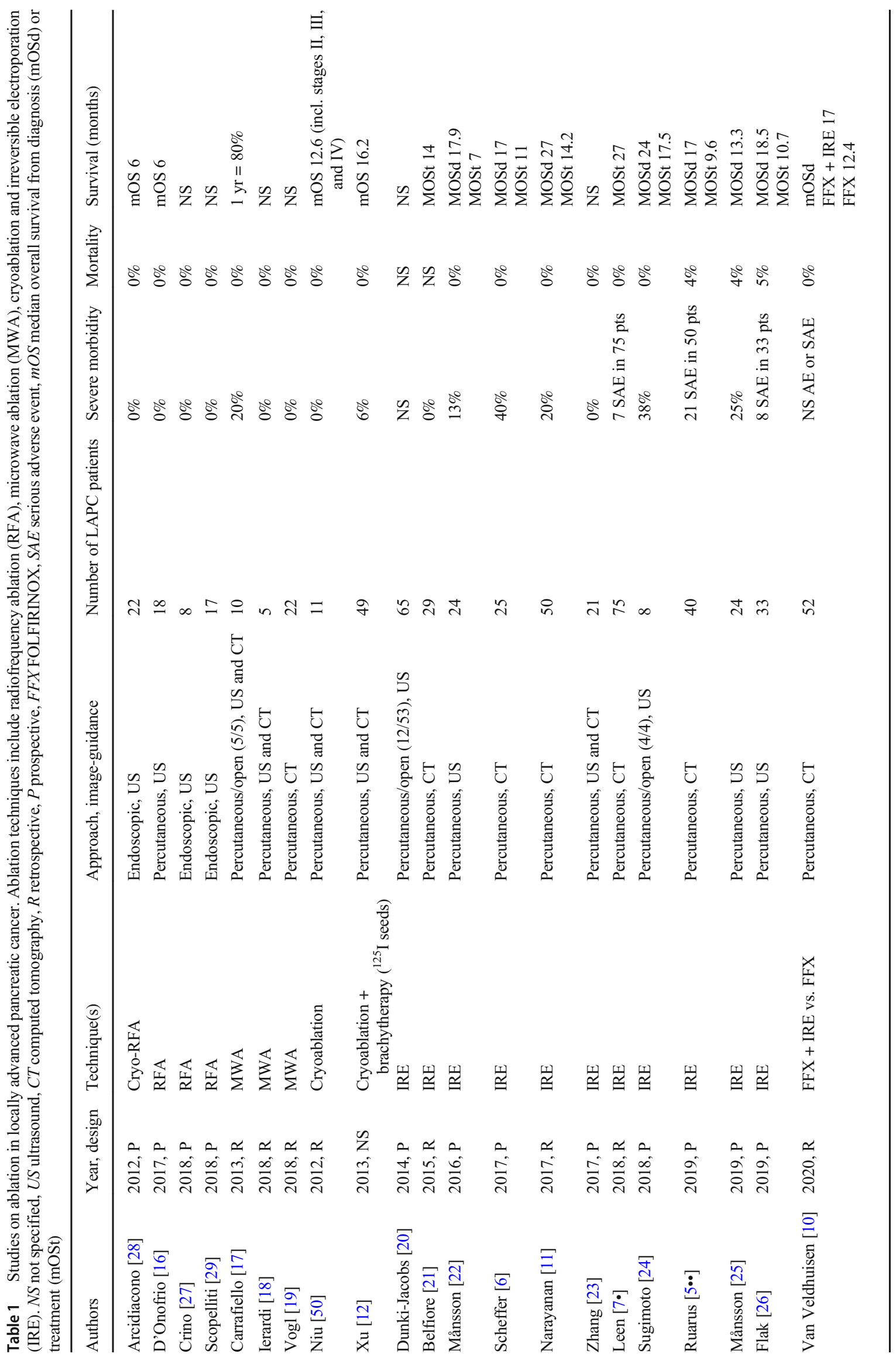




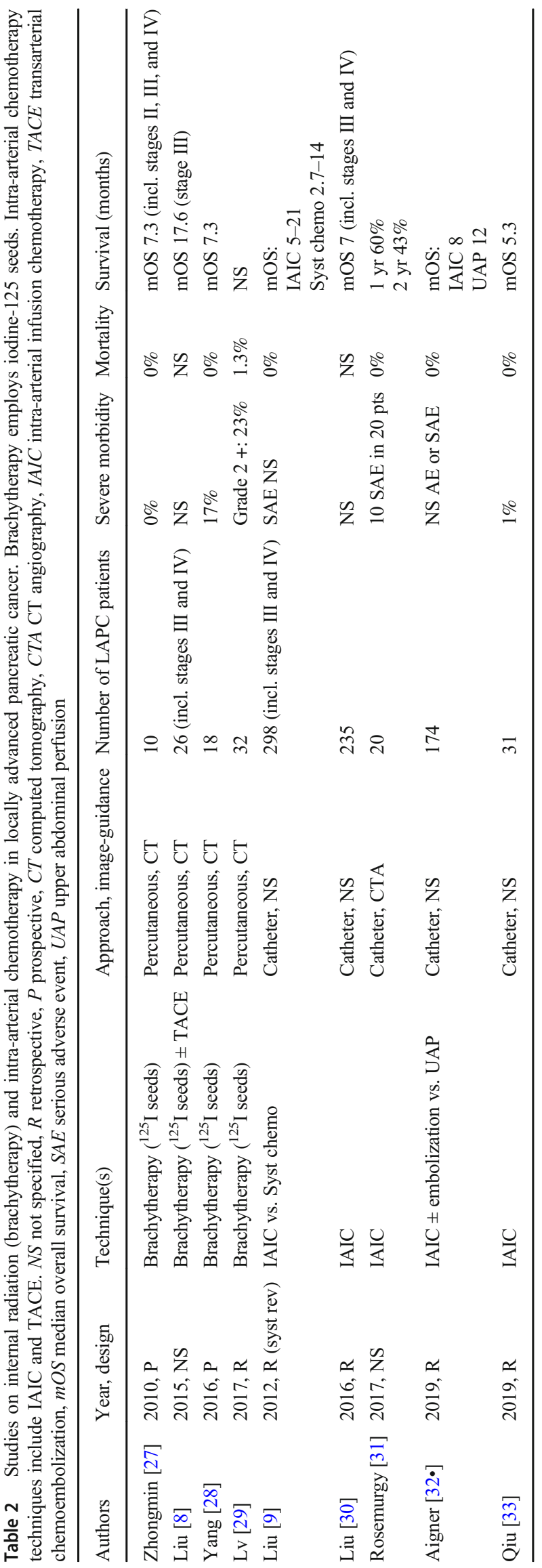

regarding procedure regimens (temperature, power, duration, minimum distance to vulnerable structures) and timing prior to or after chemo(radio)therapy remains [40, 41]. The currently recruiting randomized controlled PELICAN trial aims to determine the survival benefit of chemotherapy and cytoreductive RFA compared to sole chemotherapy (NCT03690323).

\section{Immunomodulation After RFA}

The immunomodulation presented after RFA is a result of ICD through the release of antigens and DAMPS such as interleukin (IL)-1, IL-6, IL-8, and tumor necrosis factor (TNF)- $\alpha$ [35]. Specific for thermal tissue damage is the release of a DAMP called heat shock protein (HSP)-70, involved in proper folding and transport of proteins, and believed to play a key role in the immunological response [49]. HSP-70, mainly exposed in the peripheral non-coagulative ablation zone, is elevated in the serum of patients after RFA, which can lead to an immunological anticancer response through activation and maturation of DCs [50, 51]. However, in this peripheral zone, created by diffusion of heat outwards, IL-6, HSP-70, and hypoxia-related pathways have also been implicated to stimulate outgrowth of tumor cells in this area, thus potentially causing (early) recurrences [52-55]. In the coagulative central zone, protein denaturation and destruction of the blood and lymph vessels impedes proper immune infiltration as well as antigen diffusion or transport and subsequent presentation in draining lymph nodes. Clinical evidence of an RFA-induced immune response in PDAC is currently limited to one publication. In this article, Giardino et al. analyzed pre- and post-operative peripheral blood of 10 LAPC patients and found RFA to activate adaptive immune subsets $\left(\mathrm{CD}^{+}\right.$and $\mathrm{CD}^{+} \mathrm{T}$-cells) and myeloid DCs, while maintaining stable numbers of immune inhibiting Tregs [56•].

\section{Microwave Ablation}

MWA uses electromagnetic waves to produce tissue-heating. It relies on the oscillation of polar molecules to generate frictional heat, aiming for temperatures between 80 and $150{ }^{\circ} \mathrm{C}$ to induce coagulative tissue necrosis [57]. The procedure can be performed using a sole or a cluster of MW antennas which are inserted into the tumor. An advantage of MWA over other thermal ablative techniques includes the faster heating of tissue, making it less susceptible to the heat-sink effect. In addition, MWA appears more suited for larger tumors, is less affected by tissue impedance changes and the microwaves are able to travel more efficiently through fibrous (pancreatic) tissue [58]. However, MWA ablation zones can be harder to predict, possibly leading to overtreatment and, consequently, unintentional thermal damage to adjacent structures. MWA 
can be performed during laparoscopy, laparotomy, and percutaneously.

\section{Efficacy and Safety of MWA}

Three groups previously described results following percutaneous MWA in LAPC [17-19]. They included a total of 32 patients treated under US or computed tomography (CT) guidance, mostly focusing on the technique's feasibility and safety. All reported $100 \%$ technical success rates, without any 30day mortality. Carrafielo et al. included 10 patients ( 5 percutaneous, 5 laparotomic) with LAPC unresponsive to chemotherapy and were the only group reporting severe morbidity ( $n$ $=2,20 \%)$ and survival outcomes (1-year OS of 80\%) [17]. Major complications included one (early) pancreatitis and one (late) pseudoaneurysm of the gastroduodenal artery. All articles were uniform to conclude the technique's ability to temporarily improve quality of life, its feasibility, and safety. However, comprehensive and longer term survival results are lacking, thus conclusions on the efficacy of MWA in LAPC are premature. Nonetheless, similar to RFA, a major drawback of this technique remains the use of thermal energy in a highly delicate organ surrounded by vulnerable structures.

\section{Immunomodulation After MWA}

MWA induces a similar immune response as described for RFA, with upregulation of serum HSP-70, although apparently to a lesser extent [59]. (Pre-)clinical literature on immune modulation of MWA in the context of pancreatic cancer is lacking.

\section{Cryoablation}

With cryoablation, liquid gasses such as argon or nitrogen are delivered through one or multiple cryoprobes and expand into a gaseous state at the tip of the probe through a mechanism known as the Joule-Thomson effect [60]. With temperatures as low as $-190^{\circ} \mathrm{C}$, this process causes local freezing of tissues resulting in a combination of necrotic and delayed apoptotic cell death. Cryoablation depends on four factors: rate of cooling, minimum temperature, and duration at this temperature during the procedure, and the rate of thawing. The extreme cold also induces blood coagulation followed by vascular ischemia [60]. Several freeze-thaw cycles are performed to obtain effective and successful ablation. Cryoablation requires real-time monitoring of the ice ball to ensure complete freezing and minimal injury to adjacent structures.

\section{Efficacy and Safety of Cryoablation}

To date, four articles have been published on the use of cryoablation in the context of LAPC, two in an open [61,
$62]$ and two in a percutaneous setting [12, 63]. As monotherapy, cryoablation demonstrated a mOS of 12.6 months [63], and in combination with internal radiotherapy a mOS of 16.2 months [12] was noted (neither article specified whether OS from diagnosis or treatment). Niu et al. were the only group reporting on sole percutaneous cryoablation and included patients with stage II $(n=3)$, III $(n=11)$, and IV $(n=18)$ PDAC whose tumor was deemed unresectable [63]. Clinical benefit response (based on pain scores and analgesic consumption) was $84.4 \%$, and the mOS was 12.6 months (incl. all stages). In order to overcome potentially incomplete destruction at the ablation border, Xu et al. described percutaneous cryoablation in combination with brachytherapy in LAPC $(n=49)$, demonstrating a mOS of 16.2 months with a $6 \%$ severe complication rate [12]. The freezing process can injure delicate parenchyma including the duodenum, bile ducts, or blood vessels, resulting in inflammation, fistulas, abscesses, or bleeding. Division of surrounding tissue or application of warm pads may reduce the risk of these freezing-related injuries [59].

\section{Immunomodulation After Cryoablation}

Cryoablation has been described as a potent immunostimulatory inducer among thermal ablative therapies, able to release most non-denatured proteins and induce profound DC antigen loading $[64,65]$. It has even resulted in extreme cases of inflammatory responses owing to the induced cytokine storm which increases vascular permeability, resulting in abundant tissue edema and in some cases cryoshock [66]. On the other hand, cryoablation has also been described as an immunosuppressant modality [67]. Increased levels of IL-10, an immunosuppressive cytokine that promotes Treg differentiation, have been proposed as part of the explanation for this [68, 69]. Furthermore, portions of the ablation zone may not exhibit ICD, thus impeding generation of a proper anti-tumor immune response [49]. In this regard, the rate of tissue freezing has been suggested as an important determinant of immunologic response [70]. Literature on the immune response after cryoablation in pancreatic cancer patients is currently limited to one pre-clinical study. White et al. compared early immunological responses after cryoablation and IRE in a rodent model of pancreatic cancer. They noted no significant changes in any immune cell type after cryoablation, compared to a robust intra-tumoral infiltration of macrophages and $\mathrm{CD}^{+}{ }^{+} \mathrm{T}$-cells after IRE [71].

\section{Irreversible Electroporation}

IRE is a predominantly non-thermal ablative technique which utilizes high-voltage electrical pulses (HVEPs) of up to $3000 \mathrm{~V}$ to permeabilize and destabilize the cellular membrane, leading to necrotic and (delayed) apoptotic cell death [72]. Multiple needle electrodes are placed in and 


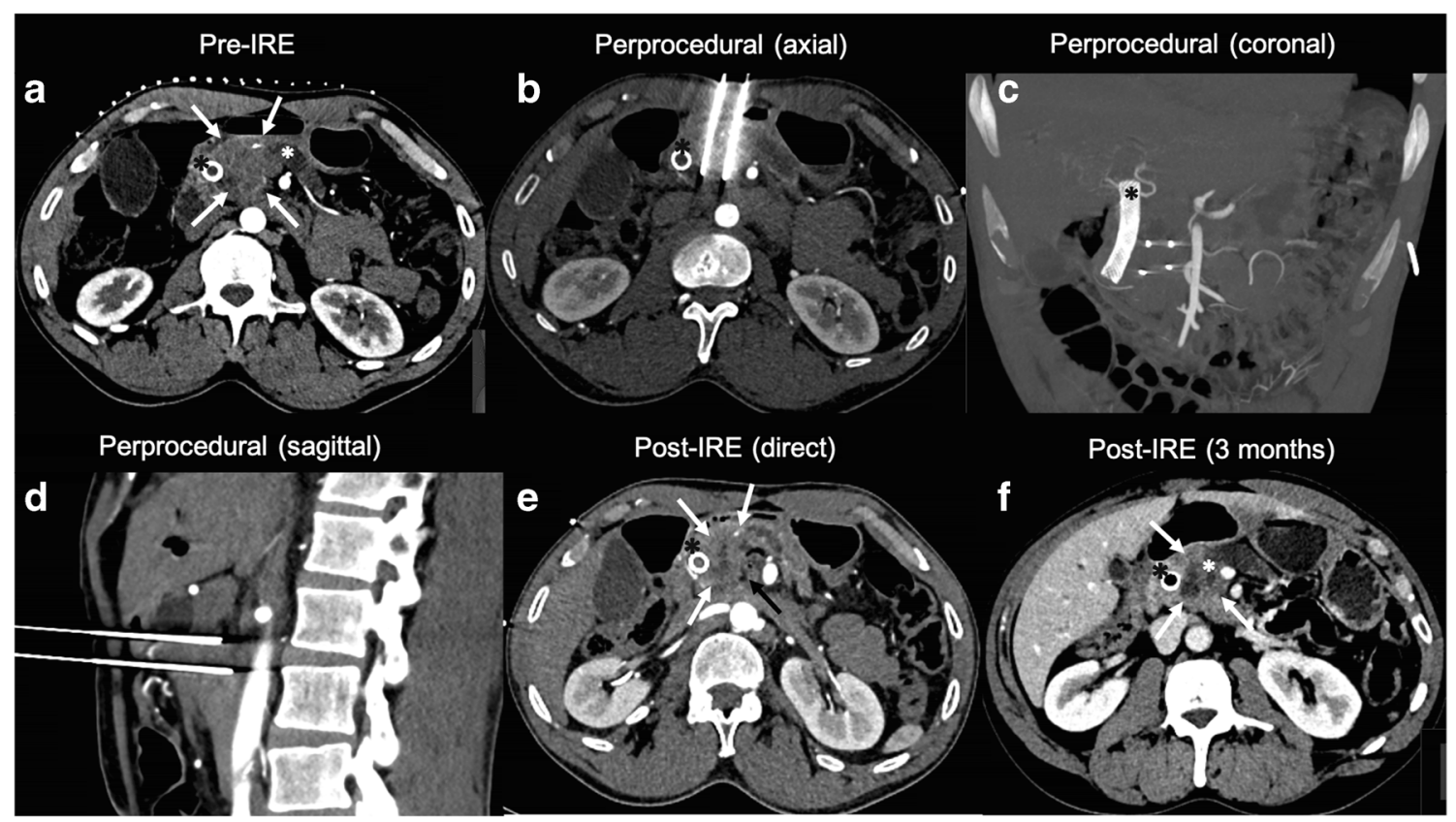

Fig. 2 CT-guided percutaneous irreversible electroporation (IRE) for locally advanced pancreatic cancer (LAPC). Sixty-two-year-old male with LAPC on the basis of involvement of the superior mesenteric artery $\left(0-90^{\circ}\right.$, although complete encasement $\left(360^{\circ}\right)$ of the first jejunal branch), involvement of the aorta $\left(0-90^{\circ}\right)$, and involvement of the superior mesenteric vein/portal vein $\left(0-90^{\circ}\right)$. A biliary stent (black asterisks in $\mathbf{a}, \mathbf{b}, \mathbf{c}, \mathbf{e}, \mathbf{f})$ was placed prior to IRE using endoscopic retrograde cholangiopancreatography (ERCP). a Perprocedural contrast enhanced (ce)-CT of the LAPC in the head of the pancreas (white arrows) and biliary stent (black asterisk) prior to IRE treatment. The white asterisk shows significant dilation of the pancreatic duct. b Perprocedural axial view of 2 of the 4 needle electrodes in situ. $\mathbf{c}$ Perprocedural coronal view of all 4 needle electrodes in situ. The needles were successfully placed, bypassing all major blood vessels. d Sagittal view of 2 of the 4 needle electrodes in situ. e ce-CT immediately after IRE. The white arrows delineate the ablation zone, wherein formation of gas pockets is clearly visible (black arrow). The gas pockets maybe the result of water electrolysis and/or vaporization. f ce-CT 3 months post-IRE demonstrates a hypointense ablation zone (white arrows). The portal vein is open; dilation of the pancreatic duct (white asterisk) remains unchanged. No evidence of local recurrence or distant metastases around the tumor, such that the entire tumor volume including a margin is encompassed. Compared to thermal ablative methods, IRE offers several advantages, especially for pancreatic tumors. The HVEPs preserve the collagen framework of adjacent delicate structures, allowing for cellular regeneration [73]. In addition, the efficacy of the HVEPs is not hindered by the heat-sink effect. For these reasons, US- or CT-guided open IRE, as stand-alone therapy $[20,24,42,74-80]$ or for margin accentuation $[76,81]$, and percutaneous IRE $[5 \bullet \bullet, 6,7 \bullet, 11$, 20-26, 82] have gained interest over the last decade for the treatment of locally advanced or recurrent pancreatic cancer. Figure 2 demonstrates a case of a 62-year-old male with LAPC successfully treated with contrast-enhanced (ce)CTguided percutaneous IRE.

\section{Safety and Efficacy of IRE}

Studies on percutaneous IRE demonstrate survival outcomes after diagnosis (mOSd) between 13.3 and 27 months (vs. 15.3-24.9 months in open IRE), and survival outcomes after treatment (mOSt) between 7 and 27 months (vs. 6.4-12 months in open IRE). A large database study has established that IRE in combination with chemotherapy (mOS 16 months) prolongs survival compared to sole chemotherapy (mOS 8 months) after propensity score matching [83]. Leen et al. reported on the largest LAPC cohort $(n=75)$ with the longest survival outcomes (mOSt 27 months). These results may in part be explained by the retrospective nature of the research, inherently leading to selection bias, in combination with favorable patient selection criteria. The largest prospective cohort was reported by Ruarus et al., who treated 40 LAPC and 10 recurrent patients using (ce)CT-guided percutaneous IRE. They reported mOSd and mOSt of 17 months and 9.6 months, respectively. Major complication rates varied substantially among studies on percutaneous IRE (0-40\%) but were generally lower compared to open procedures $(8-53 \%)$. The most frequently encountered major complications during and after IRE procedures include pancreatitis, fistulas, ileus, or delayed gastric emptying, intraabdominal hemorrhages, ulcers, portal vein thromboses, and biliary-related issues (leakage and/or cholangitis). To reduce the chances of IRE-related infections, prophylactic antibiotics are a must. Reported mortality rates after treatment varied between 0 and $6 \%$ (vs. $0-13 \%$ in an open setting). Notably, $\mathrm{Xu}$ et al. have recently published on the importance of adjuvant chemo- and/or radiotherapy after 
IRE, concluding that additive adjuvant therapy significantly improves survival [84].

\section{Immunomodulation after IRE}

Immunomodulation in IRE has been described as the most potent compared to thermal ablative techniques, specifically in terms of protein release and T-cell activation [64]. With IRE specifically, hypoxia is relieved by increasing blood vessel permeability and microvessel density, counteracting hypoxia-induced immunosuppression [85••]. In addition, the preservation of lymph vessels allows DCs to transport released antigens from the ablated area to the draining lymph nodes. Thereafter, the activated effector T-cells are able to infiltrate the residual ablated mass owing to intact blood vessel structures. Scheffer et al. have demonstrated the clinical immune modulatory effects after percutaneous IRE in the peripheral blood of 10 LAPC patients [86•]. Two weeks post-IRE, Tregs were decreased, PD- ${ }^{+}$T-cells were elevated, and boosting or de novo induction of a Wilms Tumor-1 (pancreatic TAA)-specific T-cell response was observed. These findings are consistent with a systemic and tumor-specific immune stimulatory effect. Pandit et al. also evaluated the post-IRE immune response in LAPC patients $(n=11)$ [87•], in which three Treg subsets displayed an inverse correlation with time, demonstrating attenuation of immunosuppression.

\section{Brachytherapy: lodine-125 Seed Implantation}

Iodine-125 $\left({ }^{125} \mathrm{I}\right)$ seed implantation is a form of brachytherapy, or internal radiation, and has been used in the treatment of PDAC for several decades. The seeds contain the radioactive material and can be placed inside the tumor using an implantation needle and gun [88]. The radioactive material causes direct cell death by damaging its DNA and indirect damage by producing free radicals, resulting in a mixture of lethal and sublethal damage [89]. Since the radioactive particles are embedded inside the tumor and have a small radiation radius, this allows for administration of a high radioactive dose, killing nearby tumor cells without inflicting considerable collateral damage to the surrounding tissue. An important limitation of this treatment is radiation attenuation. With a half-life of 59 days, ${ }^{125}$ I seed implantation will only have a temporary effect. As with the other local therapies, implantation can be accomplished through open [90-94] or percutaneous [8, 12, 27, 28] means under CT or US guidance, with the latter approach having shorter procedural times and quicker recovery [95].

\section{Safety and Efficacy of ${ }^{125}$ I Seed Implantation}

As stand-alone local therapy, median survival outcomes in LAPC patients percutaneously treated ranges between 7.3 and 11 months. Additional increase in survival can be achieved if ${ }^{125}$ I seed implantation is combined with other interventional modalities such as cryoablation (mOS 16.2 months) [12] or TACE (mOS 17.6 months) [8]. Reported severe morbidity varies between 0 and $17 \%$ (vs. $0-11 \%$ open setting), whereas mortality among studies was $0 \%$ (vs. $1.3 \%$ open setting). The high rate of severe morbidity reported by Yang et al. (17\%) can be explained by patient selection, including only LAPC patients whose disease was complicated by obstructive jaundice [28]. Most common (major) complications for percutaneous ${ }^{125}$ I seed implantation include pancreatitis, fistulas, seed migration, ulcers, infections, leakage, and intestinal perforations [29].

\section{Immunomodulation After ${ }^{125}$ I Seed Implantation}

Apoptosis is the predominant form of cell death in radiationbased therapies, but high doses of radiation can also lead to necrosis. Similar to other ablative therapies, paradoxical immunomodulatory effects have been reported after radiotherapy treatment [96]. Immunopermissive effects may be initiated by a combinatory release of antigens and DAMPs, followed by activation of the adaptive system. However, radiotherapy has been suggested to promote inactivation of DCs and NK cells, consequently leading to recruitment of immunosuppressive MDSCs and Tregs. There is currently no literature published on the immunomodulatory effects of internal radiation therapy in pancreatic cancer, but external radiation effects were demonstrated by Fujiwara et al. in a subcutaneous PDAC mouse model [97]. Radiotherapy appeared to induce innate immune permissive responses by activating Toll-like receptors (TLRs) and pro-inflammatory chemokines. However, effects on the adaptive system seemed double-edged as immune activating (TNF receptors) and immune suppressive (transforming growth factor (TGF)- $\beta$ ) pathway genes were upregulated. Furthermore, intra-tumoral $\mathrm{CD}^{+} \mathrm{T}$-cells remained scarce.

\section{Intra-arterial Infusion Chemotherapy/Transarterial Chemoembolization (TACE)}

(Regional) intra-arterial infusion of chemotherapy (RAIC or IAIC) and transarterial chemoembolization (TACE) are minimally invasive techniques in which (a combination of) chemotherapeutics are locally supplied through an arterially placed catheter. The latter technique (TACE) includes additional embolization agents to achieve simultaneous blocking of the vessels. IAIC and TACE are often combined with systemic chemotherapy, either in a concurrent or sequential fashion, or used as a subsequent therapy for systemic chemotherapy refractory patients. The chemotherapeutic agents are cytotoxic and non-specifically target either the DNA itself or enzymes required for DNA synthesis and repair, with the rationale that highly proliferative cancer cells are more vulnerable to this damage. IAIC and TACE have been extensively 
employed for the treatment of hepatic tumors [98], but some literature has also been published on its use in pancreatic cancer [9, 30-33]. The exact tumor location and its supplying arteries determine through which vessels the chemotherapeutic infusion will be delivered. In general, tumors with abundant blood vessels benefit more from regional infusion since this implies a greater localized concentration of the chemotherapeutics [30].

\section{Safety and Efficacy of IAIC/TACE}

A meta-analysis compared systemic administration of chemotherapy $(n=143)$ with IAIC $(n=155)$ [9]. The analysis comprised 6 randomized controlled trials (RCTs) including 298 patients with advanced pancreatic disease (stages III/IV). They concluded that IAIC resulted in increased median survival (5-21 months vs. $2.7-14$ months), superior clinical benefits (78\% vs. $29 \%$ ), and fewer overall complications (49\% vs. 71\%) and hematological side effects (61\% vs. $86 \%$ ). Although chemotherapeutic toxicity (e.g., neutropenia, thrombocytopenia) rates are lower, they can still arise in IAIC. In addition, specifically with IAIC, (post-procedural) infections or vascular dissections may occur. Although IAIC has shown to be of value, the expansion into common clinical practice is limited by the difficulty of the procedure, with i.v. chemotherapy being more readily available and cheaper. However, especially for patients resistant to standardized systemic chemotherapy, this may be a suitable neoadjuvant or palliative treatment option.

\section{Immunomodulation After (Local) Chemotherapy}

(Locoregional) Chemotherapy has been implicated to elicit tumor-specific immune responses [14, 99]. The apoptotic ICD leads to extracellular accumulation of nucleic acids (DAMPs), promoting release of type I interferon (IFN), followed by maturation of DCs and activation of effector Tcells [100]. However, to date no literature has been published specifically describing the immune response after local administration of chemotherapy in pancreatic cancer. Michelakos et al. describe clinical results in PDAC patients $(n=248)$ of whom a portion received systemic FOLFIRINOX ( \pm radiation) and were compared to untreated controls [101]. The treated group exhibited dense $\mathrm{CD}^{+} \mathrm{T}$-cell infiltration, high $\mathrm{CD}^{+} \mathrm{T}$-cell numbers, and low Treg cell density.

\section{Intra-tumoral Immunotherapy}

The aim of immunotherapy is to establish a systemic antitumor immune response. Intra-tumoral immunotherapies, in addition to their local priming effects, also enable this systemic effect yet offer one major advantage over systemic administration. Their bioavailability to the tumor and its draining lymph nodes is superior, thus allowing lower doses to suffice and consequently avoiding major systemic toxicities [102-104]. As a result, combination immunotherapies previously deemed unworkable due to severe toxicities are now feasible, with the possibility of repeat treatments [105]. Intra-tumoral infusion can be established under image-guidance, either using an endoscopic or percutaneous (needleguided) approach. Examples of these intra-tumoral immunotherapies are oncolytic viruses, cytokines, immune checkpoint inhibitors, and Toll-like receptor (TLR) agonists (Fig. 1).

Oncolytic viruses are deployed to infect tumor cells and insert genetic material into their DNA. Oncogenic pathways at play in tumor cells allow for replication of the oncolytic viruses and eventual lysis of the tumor cells, while leaving normal healthy cells unaffected. The lysed tumor cells release tumor antigens, DAMPs, and virus-derived pathogen-associated molecular patterns (PAMPs), leading to immune system activation [106]. Hirooka et al. published results of a phase 1 clinical trial in which LAPC patients $(n=10)$ were treated with EUS-guided intra-tumoral HF-10 oncolytic virus in combination with erlotinib and gemcitabine [107•]. This triple treatment was deemed safe (20\% SAEs), with a PFS of 6.3 months and OS of 15.5 months.

IL-12 is a pro-inflammatory cytokine produced by APCs in response to pathogens. It has the ability to induce differentiation of naïve $\mathrm{CD}^{+} \mathrm{T}$-cells into T-helper-1 (Th1) cells, increase cytotoxic activities of T-cells and NK cells, and inhibit or reprogram MDSCs and TAMs [108]. In a PDAC hamster model, an intra-tumoral IL-12 incorporated oncolytic virus achieved a potent anti-tumor effect [109].

Intra-tumoral administration of anti-CTLA4 and/or antiPD-1 has been shown to ensure optimal access to tumordraining lymph nodes and in mouse models it has been shown to be equally efficacious as systemic delivery without unwanted immune-related side effects accompanying systemic treatment [102-104]. In a pre-clinical model of PDAC, peritumoral anti-CTLA4 has demonstrated effective inhibition of tumor growth, with increased effector T-cell infiltration and reduced Tregs [110].

TLRs are a family of pattern recognition receptors present on the surface of macrophages and DCs, normally involved in the recognition of pathogens. Hereupon, they initiate a cascade of pro-inflammatory effects through the innate and adaptive immune system [111]. Schmidt et al. demonstrated that intra-tumoral administration of a TLR-2/6 agonist in PDAC patients $(n=10)$ with incompletely resected primary tumors resulted in an influx of lymphocytes and monocytes in wound secretion, and reversal of NK inhibition [112].

\section{Future Directions}

The immunomodulatory effects of different treatment strategies are highly variable and have yet to be fully 
elucidated in the clinical context of PDAC. Nonetheless, a transition from an immune inhibitory to a more permissive state has been presented in several studies. However, one common major limitation remains, i.e., the transient nature of the immune effect. It has been hypothesized that the antitumor immune response may become durable when these local techniques are combined with immunotherapy (Fig. 1). In a pre-clinical immunocompetent mouse model with subcutaneous PDAC, stereotactic body radiotherapy (SBRT) in combination with intra-tumoral injections of IL-12 microspheres resulted in increased IFN production and $\mathrm{CD} 8^{+} \mathrm{T}$-cell activation, followed by significant tumor reduction and even remission in some cases [113]. Zhao et al. utilized a similar PDAC mouse model, demonstrating that combined IRE and systemic anti-PD1 treatment promotes $\mathrm{CD} 8^{+} \mathrm{T}$-cell infiltration and significantly increased overall survival when compared to the controls and either IRE or anti-PD1 as monotherapy [85••]. Narayanan et al. also presented pre-clinical findings in mice with PDAC, in which IRE was combined with systemic antiPD1 and an intra-tumoral TLR-7 agonist [114•]. Compared to sole IRE, this triple strategy improved treatment response and resulted in elimination of untreated concomitant metastases. Clinically, IRE combined with NK cells $\left[115,116^{\bullet}\right]$ or allogenic V $\gamma 9 \mathrm{~V} \delta 2 \mathrm{~T}$-cell infusion [117•0] have both presented as life-prolonging therapies. These encouraging initial results warrant further exploration. The PANFIRE-III trial will combine IRE, systemic anti-PD1, and an intra-tumoral TLR-9 agonist in metastasized PDAC patients (NCT04612530).

\section{Conclusion}

PDAC is an aggressive type of cancer and maintains a highly immunosuppressive environment. The discussed interventional techniques provide cytoreduction of tumor mass in LAPC patients, which may result in prolonged survival. Furthermore, recent literature suggests that certain techniques have immunomodulatory capacities, which may be leveraged when combined with immunotherapy, possibly creating a durable anti-tumor effect. Promising initial data supports this notion of synergism between local interventional and immunotherapeutic strategies. However, definitive conclusions can only be made when large prospective (randomized controlled) trials confirm these results.

\section{Compliance with Ethical Standards}

Human and Animal Rights and Informed Consent This article does not contain any studies with human or animal subjects performed by any of the authors.

Conflict of Interest Florentine E.F. Timmer, Bart Geboers, Sanne Nieuwenhuizen, Evelien A.C. Schouten, Madelon Dijkstra, Jan J.J. de
Vries, M. Petrousjka van den Tol, Tanja D. de Gruijl, and Hester J. Scheffer declare no conflict of interest. Martijn R. Meijerink is a paid consultant for AngioDynamics, and received NanoKnife needle electrode compensation for clinical trials from AngioDynamics.

Open Access This article is licensed under a Creative Commons Attribution 4.0 International License, which permits use, sharing, adaptation, distribution and reproduction in any medium or format, as long as you give appropriate credit to the original author(s) and the source, provide a link to the Creative Commons licence, and indicate if changes were made. The images or other third party material in this article are included in the article's Creative Commons licence, unless indicated otherwise in a credit line to the material. If material is not included in the article's Creative Commons licence and your intended use is not permitted by statutory regulation or exceeds the permitted use, you will need to obtain permission directly from the copyright holder. To view a copy of this licence, visit http://creativecommons.org/licenses/by/4.0/.

\section{References}

Papers of particular interest, published recently, have been highlighted as:

- Of importance

•. Of major importance

1. Kamisawa T, Wood LD, Itoi T, Takaori K. Pancreatic cancer. Lancet. 2016;388(10039):73-85.

2. Ducreux M, Cuhna AS, Caramella C, Hollebecque A, Burtin P, Goéré D, et al. Cancer of the pancreas: ESMO Clinical Practice Guidelines for diagnosis, treatment and follow-up. Ann Oncol. 2015;26(Suppl 5):v56-68.

3. Vincent A, Herman J, Schulick R, Hruban RH, Goggins M. Pancreatic cancer. Lancet. 2011;378(9791):607-20.

4. Callery MP, Chang KJ, Fishman EK, Talamonti MS, William Traverso L, Linehan DC. Pretreatment assessment of resectable and borderline resectable pancreatic cancer: expert consensus statement. Ann Surg Oncol. 2009;16(7):1727-33.

5.• Ruarus AH, Vroomen L, Geboers B, van Veldhuisen E, Puijk RS, Nieuwenhuizen S, et al. Percutaneous Irreversible Electroporation in Locally Advanced and Recurrent Pancreatic Cancer (PANFIRE-2): a multicenter, prospective, single-arm, phase II study. Radiology. 2019:191109 This is the largest prospective trial to date on percutaneous IRE for LAPC patients, thus holding valuable data on the potential of the technique. They demonstrated survival after diagnosis of 17 months and after treatment of 9.6 months.

6. Scheffer HJ, Vroomen LG, de Jong MC, Melenhorst MC, Zonderhuis BM, Daams F, et al. Ablation of locally advanced pancreatic cancer with percutaneous irreversible electroporation: results of the phase I/II PANFIRE study. Radiology. 2017;282(2): 585-97.

7. Leen E, Picard J, Stebbing J, Abel M, Dhillon T, Wasan H. Percutaneous irreversible electroporation with systemic treatment for locally advanced pancreatic adenocarcinoma. J Gastrointest Oncol. 2018;9(2):275-81 This is the largest (retrospective) series on percutanous IRE for LAPC patients, simultaneously demonstrating the longest survival outcomes (27 months after treatment).

8. Liu B, Zhou T, Geng J, Zhang F, Wang J, Li Y. Percutaneous computed tomography-guided iodine-125 seeds implantation for 
unresectable pancreatic cancer. Indian J Cancer. 2015;52(Suppl 2):e69-74.

9. Liu F, Tang Y, Sun J, Yuan Z, Li S, Sheng J, et al. Regional intraarterial vs. systemic chemotherapy for advanced pancreatic cancer: a systematic review and meta-analysis of randomized controlled trials. PLoS One. 2012;7(7):e40847.

10. van Veldhuisen E, Vroomen LG, Ruarus AH, Derksen TC, Busch $\mathrm{OR}$, de Jong MC, et al. Value of CT-guided percutaneous irreversible electroporation added to FOLFIRINOX chemotherapy in locally advanced pancreatic cancer: a post hoc comparison. J Vasc Interv Radiol. 2020;31(10):1600-8.

11. Narayanan G, Hosein PJ, Beulaygue IC, Froud T, Scheffer HJ, Venkat SR, et al. Percutaneous image-guided irreversible electroporation for the treatment of unresectable, locally advanced pancreatic adenocarcinoma. J Vasc Interv Radiol. 2017;28(3):342-8.

12. $\mathrm{Xu} \mathrm{K}, \mathrm{Niu} \mathrm{L}, \mathrm{Mu} \mathrm{F}, \mathrm{Hu} \mathrm{Y}$. Cryosurgery in combination with brachytherapy of iodine-125 seeds for pancreatic cancer. Gland Surgery. 2013;2(2):91-9.

13. Geboers B, Ruarus AH, Nieuwenhuizen S, Puijk RS, Scheffer HJ, de Gruijl TD, et al. Needle-guided ablation of locally advanced pancreatic cancer: cytoreduction or immunomodulation by in vivo vaccination? Chin Clin Oncol. 2019;8(6):61.

14. Zitvogel L, Galluzzi L, Smyth MJ, Kroemer G. Mechanism of action of conventional and targeted anticancer therapies: reinstating immunosurveillance. Immunity. 2013;39(1):74-88.

15. Marabelle A, Andtbacka R, Harrington K, Melero I, Leidner R, de Baere T, et al. Starting the fight in the tumor: expert recommendations for the development of human intratumoral immunotherapy (HIT-IT). Annals of Oncology. 2018;29(11):2163-74.

16. D'Onofrio M, Crosara S, De Robertis R, Butturini G, Salvia R, Paiella $S$, et al. Percutaneous radiofrequency ablation of unresectable locally advanced pancreatic cancer: preliminary results. Technol Cancer Res Treat. 2017;16(3):285-94.

17. Carrafiello G, Ierardi AM, Fontana F, Petrillo M, Floridi C, Lucchina N, et al. Microwave ablation of pancreatic head cancer: safety and efficacy. J Vasc Interv Radiol. 2013;24(10):1513-20.

18. Ierardi AM, Biondetti P, Coppola A, Fumarola EM, Biasina AM, Alessio Angileri S, et al. Percutaneous microwave thermosphere ablation of pancreatic tumours. Gland Surg. 2018;7(2):59-66.

19. Vogl TJ, Panahi B, Albrecht MH, Naguib NNN, Nour-Eldin NEA, Gruber-Rouh T, et al. Microwave ablation of pancreatic tumors. Minimally Invasive Therapy \& Allied Technologies. 2018;27(1):33-40.

20. Dunki-Jacobs EM, Philips P, Martin RC 2nd. Evaluation of resistance as a measure of successful tumor ablation during irreversible electroporation of the pancreas. J Am Coll Surg. 2014;218(2): 179-87.

21. Belfiore MP, Ronza FM, Romano F, Ianniello GP, De Lucia G, Gallo C, et al. Percutaneous CT-guided irreversible electroporation followed by chemotherapy as a novel neoadjuvant protocol in locally advanced pancreatic cancer: our preliminary experience. Int J Surg. 2015;21(Suppl 1):S34-S9.

22. Månsson C, Brahmstaedt R, Nilsson A, Nygren P, Karlson BM. Percutaneous irreversible electroporation for treatment of locally advanced pancreatic cancer following chemotherapy or radiochemotherapy. Eur J Surg Oncol. 2016;42(9):1401-6.

23. Zhang Y, Shi J, Zeng J, Alnagger M, Zhou L, Fang G, et al. Percutaneous irreversible electroporation for ablation of locally advanced pancreatic cancer: experience from a Chinese institution. Pancreas. 2017;46(2):e12-e4.

24. Sugimoto K, Moriyasu F, Tsuchiya T, Nagakawa Y, Hosokawa Y, Saito K, et al. Irreversible electroporation for nonthermal tumor ablation in patients with locally advanced pancreatic cancer: initial clinical experience in Japan. Internal medicine (Tokyo, Japan). 2018;57(22):3225-31.
25. Mansson C, Brahmstaedt R, Nygren P, Nilsson A, Urdzik J, Karlson BM. Percutaneous irreversible electroporation as firstline treatment of locally advanced pancreatic cancer. Anticancer Res. 2019;39(5):2509-12.

26. Flak RV, Stender MT, Jensen TM, Andersen KL, Henriksen SD, Mortensen PB, et al. Treatment of locally advanced pancreatic cancer with irreversible electroporation-a Danish single center study of safety and feasibility. Scand J Gastroenterol. 2019;54(2):252-8.

27. Zhongmin W, Yu L, Fenju L, Kemin C, Gang H. Clinical efficacy of CT-guided iodine-125 seed implantation therapy in patients with advanced pancreatic cancer. European radiology. 2010;20(7):1786-91.

28. Yang M, Yan Z, Luo J, Liu Q, Zhang W, Ma J, et al. A pilot study of intraluminal brachytherapy using (125)I seed strand for locally advanced pancreatic ductal adenocarcinoma with obstructive jaundice. Brachytherapy. 2016;15(6):859-64.

29. Lv WF, Lu D, Xiao JK, Mukhiya G, Tan ZX, Cheng DL, et al. The side effects and complications of percutaneous iodine- 125 seeds implantation under CT-guide for patients with advanced pancreatic cancer. Medicine (Baltimore). 2017;96(52):e9535.

30. Liu X, Yang X, Zhou G, Chen Y, Li C, Wang X. Gemcitabinebased regional intra-arterial infusion chemotherapy in patients with advanced pancreatic adenocarcinoma. Medicine (Baltimore). 2016;95(11):e3098.

31. Rosemurgy AS, Ross SB, Vitulli PL, Malek R, Li J, Agah R. Safety Study of Targeted and localized intra-arterial delivery of gemcitabine in patients with locally advanced pancreatic adenocarcinoma. J Pancreat Cancer. 2017;3(1):58-65.

32. Aigner KR, Gailhofer S, Selak E, Aigner K. Intra-arterial infusion chemotherapy versus isolated upper abdominal perfusion for advanced pancreatic cancer: a retrospective cohort study on 454 patients. J Cancer Res Clin Oncol. 2019;145(11):2855-62 This large retrospective study compared two chemotherapy infusion techniques (IAIC and UAP), including 174 LAPC patients. They demonstrated that IAIC was able to achieve survival outcomes of 8 months.

33. Qiu B, Zhang X, Tsauo J, Zhao H, Gong T, Li J, et al. Transcatheter arterial infusion for pancreatic cancer: a 10 -year National Cancer Center experience in 115 patients and literature review. Abdom Radiol (NY). 2019;44(8):2801-8.

34. Chu KF, Dupuy DE. Thermal ablation of tumours: biological mechanisms and advances in therapy. Nature reviews Cancer. 2014;14(3):199-208.

35. Mehta A, Oklu R, Sheth RA. Thermal ablative therapies and immune checkpoint modulation: can locoregional approaches effect a systemic response? Gastroenterol Res Pract. 2016;2016: 9251375.

36. Bang JY, Sutton B, Hawes RH, Varadarajulu S. EUS-guided celiac ganglion radiofrequency ablation versus celiac plexus neurolysis for palliation of pain in pancreatic cancer: a randomized controlled trial (with videos). Gastrointest Endosc. 2019;89(1): 58-66.e3.

37. Casadei R, Ricci C, Pezzilli R, Serra C, Calculli L, MorselliLabate AM, et al. A prospective study on radiofrequency ablation locally advanced pancreatic cancer. Hepatobiliary Pancreat Dis Int. 2010;9(3):306-11.

38. Girelli R, Frigerio I, Salvia R, Barbi E, Tinazzi Martini P, Bassi C. Feasibility and safety of radiofrequency ablation for locally advanced pancreatic cancer. Br J Surg. 2010;97(2):220-5.

39. Girelli R, Frigerio I, Giardino A, Regi P, Gobbo S, Malleo G, et al. Results of 100 pancreatic radiofrequency ablations in the context of a multimodal strategy for stage III ductal adenocarcinoma. Langenbecks Arch Surg. 2013;398(1):63-9.

40. Cantore M, Girelli R, Mambrini A, Frigerio I, Boz G, Salvia R, et al. Combined modality treatment for patients with locally 
advanced pancreatic adenocarcinoma. Br J Surg. 2012;99(8): 1083-8.

41. Frigerio I, Girelli R, Giardino A, Regi P, Salvia R, Bassi C. Short term chemotherapy followed by radiofrequency ablation in stage III pancreatic cancer: results from a single center. J Hepatobiliary Pancreat Sci. 2013;20(6):574-7.

42. Paiella S, Butturini G, Frigerio I, Salvia R, Armatura G, Bacchion $\mathrm{M}$, et al. Safety and feasibility of irreversible electroporation (IRE) in patients with locally advanced pancreatic cancer: results of a prospective study. Digestive Surgery. 2015;32(2):90-7.

43. Fegrachi S, Walma MS, de Vries JJJ, van Santvoort HC, Besselink MG, von Asmuth EG, et al. Safety of radiofrequency ablation in patients with locally advanced, unresectable pancreatic cancer: a phase II study. Eur J Surg Oncol. 2019;45(11):2166-72.

44. Crinò SF, D’Onofrio M, Bernardoni L, Frulloni L, Iannelli M, Malleo G, et al. EUS-guided radiofrequency ablation (EUSRFA) of solid pancreatic neoplasm using an 18-gauge needle electrode: feasibility, safety, and technical success. J Gastrointestin Liver Dis. 2018;27(1):67-72.

45. Arcidiacono PG, Carrara S, Reni M, Petrone MC, Cappio S, Balzano G, et al. Feasibility and safety of EUS-guided cryothermal ablation in patients with locally advanced pancreatic cancer. Gastrointest Endosc. 2012;76(6):1142-51.

46. Scopelliti F, Pea A, Conigliaro R, Butturini G, Frigerio I, Regi P, et al. Technique, safety, and feasibility of EUS-guided radiofrequency ablation in unresectable pancreatic cancer. Surg Endosc. 2018;32(9):4022-8.

47. Ruarus A, Vroomen L, Puijk R, Scheffer H, Meijerink M. Locally advanced pancreatic cancer: a review of local ablative therapies. Cancers (Basel). 2018;10(1):16.

48. Fegrachi S, Besselink MG, van Santvoort HC, van Hillegersberg R, Molenaar IQ. Radiofrequency ablation for unresectable locally advanced pancreatic cancer: a systematic review. HPB (Oxford). 2014;16(2):119-23.

49. Slovak R, Ludwig JM, Gettinger SN, Herbst RS, Kim HS. Immuno-thermal ablations-boosting the anticancer immune response. J Immunother Cancer. 2017;5(1):78.

50. den Brok MH, Sutmuller RP, Nierkens S, Bennink EJ, Frielink C, Toonen LW, et al. Efficient loading of dendritic cells following cryo and radiofrequency ablation in combination with immune modulation induces anti-tumour immunity. $\mathrm{Br} \mathrm{J}$ Cancer. 2006;95(7):896-905.

51. Haen SP, Gouttefangeas C, Schmidt D, Boss A, Clasen S, von Herbay A, et al. Elevated serum levels of heat shock protein 70 can be detected after radiofrequency ablation. Cell Stress Chaperones. 2011;16(5):495-504.

52. Wan J, Wu W, Huang Y, Ge W, Liu S. Incomplete radiofrequency ablation accelerates proliferation and angiogenesis of residual lung carcinomas via HSP70/HIF-1 $\alpha$. Oncol Rep. 2016;36(2):659-68.

53. Nijkamp MW, van der Bilt JD, de Bruijn MT, Molenaar IQ, Voest EE, van Diest PJ, et al. Accelerated perinecrotic outgrowth of colorectal liver metastases following radiofrequency ablation is a hypoxia-driven phenomenon. Ann Surg. 2009;249(5):814-23.

54. Gao S, Pu N, Yin H, Li J, Chen Q, Yang M, et al. Radiofrequency ablation in combination with an mTOR inhibitor restrains pancreatic cancer growth induced by intrinsic HSP70. Ther Adv Med Oncol. 2020;12:1758835920953728.

55. Rozenblum N, Zeira E, Bulvik B, Gourevitch S, Yotvat H, Galun $\mathrm{E}$, et al. Radiofrequency ablation: inflammatory changes in the periablative zone can induce global organ effects, including liver regeneration. Radiology. 2015;276(2):416-25.

56. Giardino A, Innamorati G, Ugel S, Perbellini O, Girelli R, Frigerio I, et al. Immunomodulation after radiofrequency ablation of locally advanced pancreatic cancer by monitoring the immune response in 10 patients. Pancreatology. 2017;17(6):962-6 This study published the first clinical results of RFA-induced immune response in LAPC patients. They demonstrated that RFA increased $\mathrm{CD}^{+}$and $\mathrm{CD8}^{+}$T-cells, while mainainting stable Treg numbers.

57. Lubner MG, Brace CL, Hinshaw JL, Lee FT. Microwave tumor ablation: mechanism of action, clinical results, and devices. Journal of Vascular and Interventional Radiology. 2010;21(8, Supplement):S192-203.

58. Brace CL. Microwave tissue ablation: biophysics, technology, and applications. Crit Rev Biomed Eng. 2010;38(1):65-78.

59. Ahmad F, Gravante G, Bhardwaj N, Strickland A, Basit R, West $\mathrm{K}$, et al. Renal effects of microwave ablation compared with radiofrequency, cryotherapy and surgical resection at different volumes of the liver treated. Liver Int. 2010;30(9):1305-14.

60. Erinjeri JP, Clark TW. Cryoablation: mechanism of action and devices. J Vasc Interv Radiol. 2010;21(8 Suppl):S187-91.

61. Li J, Chen X, Yang H, Wang X, Yuan D, Zeng Y, et al. Tumour cryoablation combined with palliative bypass surgery in the treatment of unresectable pancreatic cancer: a retrospective study of 142 patients. Postgrad Med J. 2011;87(1024):89-95.

62. Song ZG, Hao JH, Gao S, Gao CT, Tang Y, Liu JC. The outcome of cryoablation in treating advanced pancreatic cancer: a comparison with palliative bypass surgery alone. J Dig Dis. 2014;15(10): 561-9.

63. Niu L, He L, Zhou L, Mu F, Wu B, Li H, et al. Percutaneous ultrasonography and computed tomography guided pancreatic cryoablation: feasibility and safety assessment. Cryobiology. 2012;65(3):301-7.

64. Shao Q, O'Flanagan S, Lam T, Roy P, Pelaez F, Burbach BJ, et al. Engineering $T$ cell response to cancer antigens by choice of focal therapeutic conditions. Int J Hyperthermia. 2019;36(1):130-8.

65. den Brok MHMGM, Sutmuller RPM, Nierkens S, Bennink EJ, Frielink C, Toonen LWJ, et al. Efficient loading of dendritic cells following cryo and radiofrequency ablation in combination with immune modulation induces anti-tumour immunity. British Journal of Cancer. 2006;95(7):896-905.

66. Chapman WC, Debelak JP, Wright Pinson C, Washington MK, Atkinson JB, Venkatakrishnan A, et al. Hepatic cryoablation, but not radiofrequency ablation, results in lung inflammation. Ann Surg. 2000;231(5):752-61.

67. Shibata T, Suzuki K, Yamashita T, Takeichi N, Mark M, Hosokawa M, et al. Immunological analysis of enhanced spontaneous metastasis in WKA rats following cryosurgery. Anticancer Res. 1998;18(4a):2483-6.

68. Adeegbe DO, Nishikawa $\mathrm{H}$. Natural and induced T regulatory cells in cancer. Front Immunol. 2013;4:190.

69. Takaki H, Imai N, Thomas CT, Yamakado K, Yarmohammadi H, Ziv E, et al. Changes in peripheral blood T-cell balance after percutaneous tumor ablation. Minim Invasive Ther Allied Technol. 2017;26(6):331-7.

70. Sabel MS, Su G, Griffith KA, Chang AE. Rate of freeze alters the immunologic response after cryoablation of breast cancer. Ann Surg Oncol. 2010;17(4):1187-93.

71. White SB, Zhang Z, Chen J, Gogineni VR, Larson AC. Early immunologic response of irreversible electroporation versus cryoablation in a rodent model of pancreatic cancer. J Vasc Interv Radiol. 2018;29(12):1764-9.

72. Geboers B, Scheffer HJ, Graybill PM, Ruarus AH, Nieuwenhuizen S, Puijk RS, et al. High-voltage electrical pulses in oncology: irreversible electroporation, electrochemotherapy, gene electrotransfer, electrofusion, and electroimmunotherapy. Radiology. 2020;295(2):254-72.

73. Vogel JA, Vroomen LGPH, Srimathveeravalli G. The effect of irreversible electroporation on blood vessels, bile ducts, urinary tract, intestines, and nerves. In: Meijerink MR, Scheffer HJ, Narayanan G, editors. Irreversible electroporation in clinical practice. Cham: Springer International Publishing; 2018. p. 81-94. 
74. Yang PC, Huang KW, Pua U, Kim MD, Li SP, Li XY, et al. Prognostic factor analysis of irreversible electroporation for locally advanced pancreatic cancer-a multi-institutional clinical study in Asia. Eur J Surg Oncol. 2020;46(5):811-7.

75. Kwon JH, Chung MJ, Park JY, Lee HS, Hwang HK, Kang CM, et al. Initial experience of irreversible electroporation for locally advanced pancreatic cancer in a Korean population. Acta Radiol. 2020;284185120917118.

76. Martin RC 2nd, Kwon D, Chalikonda S, Sellers M, Kotz E, Scoggins C, et al. Treatment of 200 locally advanced (stage III) pancreatic adenocarcinoma patients with irreversible electroporation: safety and efficacy. Ann Surg. 2015;262(3):486-94 discussion 92-4.

77. Kluger MD, Epelboym I, Schrope BA, Mahendraraj K, Hecht EM, Susman J, et al. Single-institution experience with irreversible electroporation for T4 pancreatic cancer: first 50 patients. Annals of surgical oncology. 2016;23(5):1736-43.

78. Lambert L, Horejs J, Krska Z, Hoskovec D, Petruzelka L, Krechler T, et al. Treatment of locally advanced pancreatic cancer by percutaneous and intraoperative irreversible electroporation: general hospital cancer center experience. Neoplasma. 2016;63(2):269-73.

79. Vogel JA, Rombouts SJ, de Rooij T, van Delden OM, Dijkgraaf MG, van Gulik TM, et al. Induction chemotherapy followed by resection or irreversible electroporation in locally advanced pancreatic cancer (IMPALA): a prospective cohort study. Ann Surg Oncol. 2017;24(9):2734-43.

80. Yan L, Chen YL, Su M, Liu T, Xu K, Liang F, et al. A singleinstitution experience with open irreversible electroporation for locally advanced pancreatic carcinoma. Chin Med J (Engl). 2016;129(24):2920-5.

81. Simmerman E, Chung J, Lawson A, Kruse E. Application of irreversible electroporation ablation as adjunctive treatment for margin enhancement: safety and efficacy. J Surg Res. 2020;246:2608 .

82. Belfiore G, Belfiore MP, Reginelli A, Capasso R, Romano F, Ianniello GP, et al. Concurrent chemotherapy alone versus irreversible electroporation followed by chemotherapy on survival in patients with locally advanced pancreatic cancer. Med Oncol. 2017;34(3):38.

83. He C, Huang X, Zhang Y, Cai Z, Lin X, Li S. Comparison of survival between irreversible electroporation followed by chemotherapy and chemotherapy alone for locally advanced pancreatic cancer. Front Oncol. 2020;10:6.

84. Xu K, Chen Y, Su J, Su M, Yan L. Irreversible electroporation and adjuvant chemoradiotherapy for locally advanced pancreatic carcinoma. J Cancer Res Ther. 2020;16(2):280-5.

85.• Zhao J, Wen X, Tian L, Li T, Xu C, Wen X, et al. Irreversible electroporation reverses resistance to immune checkpoint blockade in pancreatic cancer. Nature Communications. 2019;10(1): 899 This was the first pre-clinical study in mice combining IRE with immune checkpoint inhibitors. They achieved promising durable results using this combination treatment, whilst either as monotherapy only demonstrated marginal improvement compared to the controls.

86. • Scheffer HJ, AGM S, Geboers B, LGPH V, Ruarus A, de Bruijn $\mathrm{B}$, et al. Irreversible electroporation of locally advanced pancreatic cancer transiently alleviates immune suppression and creates a window for antitumor $\mathrm{T}$ cell activation. Oncoimmunology. 2019;8(11):1652532 Along with Pandit et al., the first clinical results of IRE-induced immune response in LAPC patients. The results demonstrated a transient alleviation of an immunesuppressive state, with elevation of $\mathrm{CD4}^{+} \mathrm{PD}^{+}$and $\mathrm{CD8}^{+} \mathrm{PD1}^{+}{ }^{+}$-cells and a decrease in Tregs.

87. Pandit H, Hong YK, Li Y, Rostas J, Pulliam Z, Li SP, et al. Evaluating the regulatory immunomodulation effect of irreversible electroporation (IRE) in pancreatic adenocarcinoma. Ann Surg Oncol. 2019;26(3):800-6 Along with Scheffer et al., the first clinical results of IRE-induced immune response in LAPC patients. Their results demonstrate an inverse correlation of Tregs with time after IRE treatment.

88. Gai B, Zhang F. Chinese expert consensus on radioactive $<$ sup $>125<$ sup $>$ I seeds interstitial implantation brachytherapy for pancreatic cancer. Journal of Cancer Research and Therapeutics. 2018;14(7):1455-62.

89. Galluzzi L, Maiuri MC, Vitale I, Zischka H, Castedo M, Zitvogel L, et al. Cell death modalities: classification and pathophysiological implications. Cell Death Differ. 2007;14(7):1237-43.

90. Zou YP, Li WM, Zheng F, Li FC, Huang H, Du JD, et al. Intraoperative radiofrequency ablation combined with 125 iodine seed implantation for unresectable pancreatic cancer. World $\mathrm{J}$ Gastroenterol. 2010;16(40):5104-10.

91. Li CG, Zhou ZP, Jia YZ, Tan XL, Song YY. Radioactive (125)I seed implantation for locally advanced pancreatic cancer: a retrospective analysis of 50 cases. World J Clin Cases. 2020;8(17): 3743-50.

92. Y-f L, Z-q L, Y-s Z, Dong L-m, Wang C-y, S-m G, et al. Implantation of radioactive 125I seeds improves the prognosis of locally advanced pancreatic cancer patients: a retrospective study. Journal of Huazhong University of Science and Technology [Medical Sciences]. 2016;36(2):205-10.

93. Wang H, Wang J, Jiang Y, Li J, Tian S, Ran W, et al. The investigation of 125I seed implantation as a salvage modality for unresectable pancreatic carcinoma. J Exp Clin Cancer Res. 2013;32(1):106.

94. Zheng Z, Xu Y, Zhang S, Pu G, Cui C. Surgical bypass and permanent iodine-125 seed implantation vs. surgical bypass for the treatment of pancreatic head cancer. Oncol Lett. 2017;14(3): 2838-44.

95. Jia SN, Wen FX, Gong TT, Li X, Wang HJ, Sun YM, et al. A review on the efficacy and safety of iodine-125 seed implantation in unresectable pancreatic cancers. Int J Radiat Biol. 2020;96(3): 383-9.

96. Carvalho HA, Villar RC. Radiotherapy and immune response: the systemic effects of a local treatment. Clinics (Sao Paulo). 2018;73(suppl 1):e557s.

97. Fujiwara K, Saung MT, Jing H, Herbst B, Zarecki M, Muth S, et al. Interrogating the immune-modulating roles of radiation therapy for a rational combination with immune-checkpoint inhibitors in treating pancreatic cancer. Journal for ImmunoTherapy of Cancer. 2020;8(2):e000351.

98. Liu W, Song QK, Xing BC. A systematic review and metaanalysis to reappraise the role of adjuvant hepatic arterial infusion for colorectal cancer liver metastases. Int J Colorectal Dis. 2015;30(8):1091-102.

99. Sodergren MH, Mangal N, Wasan H, Sadanandam A, Balachandran VP, Jiao LR, et al. Immunological combination treatment holds the key to improving survival in pancreatic cancer. J Cancer Res Clin Oncol. 2020;146(11):2897-911.

100. Galluzzi L, Humeau J, Buqué A, Zitvogel L. Kroemer G. Nature Reviews Clinical Oncology: Immunostimulation with chemotherapy in the era of immune checkpoint inhibitors; 2020.

101. Michelakos T, Cai L, Villani V, Sabbatino F, Kontos F, Fernández-Del Castillo $\mathrm{C}$, et al. Tumor microenvironment immune response in pancreatic ductal adenocarcinoma patients treated with neoadjuvant therapy. J Natl Cancer Inst. 2020.

102. Fransen MF, van der Sluis TC, Ossendorp F, Arens R, Melief CJM. Controlled local delivery of CTLA-4 blocking antibody induces CD8+ T-cell-dependent tumor eradication and decreases risk of toxic side effects. Clinical Cancer Research. 2013;19(19): 5381-9. 
103. Fransen MF, Schoonderwoerd M, Knopf P, MGM C, LJAC H, Kneilling M, et al. Tumor-draining lymph nodes are pivotal in PD1/PD-L1 checkpoint therapy. JCI Insight. 2018;3(23).

104. Francis DM, Manspeaker MP, Schudel A, Sestito LF, O'Melia MJ, Kissick HT, et al. Blockade of immune checkpoints in lymph nodes through locoregional delivery augments cancer immunotherapy. Science Translational Medicine. 2020;12(563):eaay3575.

105. Marabelle A, Tselikas L, de Baere T, Houot R. Intratumoral immunotherapy: using the tumor as the remedy. Annals of Oncology. 2017;28:xii33-43.

106. Hemminki O, dos Santos JM, Hemminki A. Oncolytic viruses for cancer immunotherapy. Journal of Hematology \& Oncology. 2020;13(1):84.

107. Hirooka Y, Kasuya H, Ishikawa T, Kawashima H, Ohno E, Villalobos IB, et al. A Phase I clinical trial of EUS-guided intratumoral injection of the oncolytic virus, HF10 for unresectable locally advanced pancreatic cancer. BMC Cancer. 2018;18(1):596 One of the first clinical studies publishing on intra-tumoral injection of an oncolytic virus in combination with erlotinib and gemcitabine in LAPC patients, concluding its safety (SAE 20\%), with PFS of 6.3 months and OS of 15.5 months.

108. Nguyen KG, Vrabel MR, Mantooth SM, Hopkins JJ, Wagner ES, Gabaldon TA, et al. Localized interleukin-12 for cancer immunotherapy. Frontiers in Immunology. 2020;11:2510.

109. Bortolanza S, Bunuales M, Otano I, Gonzalez-Aseguinolaza G, Ortiz-de-Solorzano C, Perez D, et al. Treatment of pancreatic cancer with an oncolytic adenovirus expressing interleukin-12 in Syrian hamsters. Mol Ther. 2009;17(4):614-22.

110. Sandin LC, Eriksson F, Ellmark P, Loskog ASI, Tötterman TH, Mangsbo SM. Local CTLA4 blockade effectively restrains experimental pancreatic adenocarcinoma growth in vivo. Oncoimmunology. 2014;3(1):e27614.

111. Krieg AM. Toll-like receptor 9 (TLR9) agonists in the treatment of cancer. Oncogene. 2008;27(2):161-7.

112. Schmidt J, Welsch T, Jäger D, Mühlradt PF, Büchler MW, Märten A. Intratumoural injection of the toll-like receptor-2/6 agonist 'macrophage-activating lipopeptide-2' in patients with pancreatic carcinoma: a phase I/II trial. Br J Cancer. 2007;97(5):598-604.
113. Mills BN, Connolly KA, Ye J, Murphy JD, Uccello TP, Han BJ, et al. Stereotactic body radiation and interleukin-12 combination therapy eradicates pancreatic tumors by repolarizing the immune microenvironment. Cell Rep. 2019;29(2):406-21.e5.

114. JSS N, Ray P, Hayashi T, Whisenant TC, Vicente D, Carson DA, et al. Irreversible electroporation combined with checkpoint blockade and TLR7 stimulation induces antitumor immunity in a murine pancreatic cancer model. Cancer Immunol Res. 2019;7(10):1714-26 This study built on the design of Zhao et al., combining IRE with immune checkpoint inhibitors and an intra-tumoral TLR-7. This triple treatment improved treatment responses and resulted in elimination of untreated concomitant metastases.

115. Lin M, Alnaggar M, Liang S, Wang X, Liang Y, Zhang M, et al. An important discovery on combination of irreversible electroporation and allogeneic natural killer cell immunotherapy for unresectable pancreatic cancer. Oncotarget. 2017;8(60):101795807.

116. Pan Q, Hu C, Fan Y, Wang Y, Li R, Hu X. Efficacy of irreversible electroporation ablation combined with natural killer cells in treating locally advanced pancreatic cancer. Journal of BUON : official journal of the Balkan Union of Oncology. 2020;25(3): 1643-9 This clinical study demonstrated the significantly superior overall response rate of LAPC patients $(n=92)$ treated with IRE + NK cells, compared to sole IRE.

117.• Lin M, Zhang X, Liang S, Luo H, Alnaggar M, Liu A, et al. Irreversible electroporation plus allogenic $\mathrm{V} \gamma 9 \mathrm{~V} \delta 2 \mathrm{~T}$ cells enhances antitumor effect for locally advanced pancreatic cancer patients. Signal Transduction and Targeted Therapy. 2020;5(1): 215 This is the first clinical study combining IRE with $\gamma \delta$ T cells in LAPC patients $(n=62)$. Patients were randomized to receive IRE alone $(n=32)$ or IRE $+\gamma \delta$ T cells $(n=30)$, the latter group achieving longer progression-free (8.5 vs. 11 months) and overall survival (11 vs. 14.5 months).

Publisher's Note Springer Nature remains neutral with regard to jurisdictional claims in published maps and institutional affiliations. 